\title{
Cuando la ultraderecha cita a Machado. Los agujeros en la memoria democrática y el papel de la literatura
}

Isaac RosA

Escritor

\begin{abstract}
En esta contribución, se habla de literatura -de la manera en la que la literatura ha representado el pasado-y de política -en concreto, de los efectos de las deficiencias de la democracia española que hoy está en grave crisis-. Se hace desde el presente más inmediato (febrero de 20I9), y por supuesto partiendo de Machado. A partir de algunas anécdotas, se muestra cómo este uso se hace desde la ignorancia más que desde la provocación, y sin encontrar siempre el rechazo de la ciudadanía que no sabe demasiado de la vida y muerte del poeta. Esa imagen, la ultraderecha usando a Machado, refleja bien el momento actual y sirve de hilo rojo a la presente reflexión.
\end{abstract}

Keywords: Antonio Machado, literatura, política, ultraderecha, memoria democrática, democracia.

Se cumplen ochenta años de la muerte de Antonio Machado en Collioure, y se han sucedido homenajes, actos, publicaciones y opiniones, que en todos los casos leían o releían a Machado para el presente, con intereses políticos ${ }^{\mathrm{I}}$.

Un ejemplo: Sevilla, diciembre de 20I8, campaña para las elecciones autonómicas andaluzas. En un mitin del partido ultraderechista Vox, ante más de tres mil personas, la presidenta del partido en Sevilla comienza el acto citando unos versos de Antonio Machado, los más conocidos y utilizados, los más queridos por quienes buscan un Machado blanco, apolítico y universal: «Caminante son tus huellas el camino y nada más...».

De entrada, ningún problema en que alguien cite a Machado, incluso siendo la presidenta de un partido ultraderechista. Pero sus palabras fueron acompañadas por el público con gritos de "Arriba España", y tras ella intervinieron oradores que prometían perseguir y penalizar la inmigración, defender las fronteras porque «en España no cabe todo el mundo y los españoles primero", acabar con las ONGs que auxilian a los refugiados en alta mar, derogar la ley andaluza de memoria democrática, defender la catolici-

I Nota de la editora: El texto que se ofrece aquí ha sido (re)elaborado por Isaac Rosa en otoño de 2019 a partir de la conferencia que dictó en la Universidad de Berna en abril del mismo año con motivo de su participación en la mesa Homenaje a Antonio Machado y María Zambrano. Antígonas españolas: memoria histórica y exilio (dir. Bénédicte Vauthier). No se incluyen las referencias bibliografícas exactas de las obras citadas o mencionadas por el autor. 
dad de la catedral de Córdoba frente a quienes quieren resaltar su condición histórica de mezquita, o acabar con las políticas de género, que son «invento de una ideología perversa, el feminismo». Todo muy machadiano, como confirmará cualquier lector atento del poeta sevillano.

Días después de esas elecciones, el nuevo presidente andaluz, del conservador Partido Popular, y que ha conseguido la presidencia gracias al apoyo de la ultraderecha, citó a Antonio Machado en su discurso de investidura: «Hoy es siempre todavía», y recordó también a García Lorca. Machado y Lorca le sirvieron como preámbulo de un discurso en el que anunció la próxima liquidación de la ley de memoria democrática, para sustituirla por una incierta «ley de concordia».

Insisto, ningún problema en que cualquiera cite a Machado y lo haga suyo. Al contrario, me parecería estupendo que Antonio Machado fuese el referente que uniese a españoles de distinta ideología y se reafirmase así como el gran poeta español. El problema es cuando se vacía a Antonio Machado de su compromiso no ya solo político, social, republicano, sino hasta de su humanismo, citándolo en la misma frase junto a propuestas de ultraderecha.

Me gustaría evocar aún otro episodio machadiano, de fechas recientes: el presidente del gobierno español, Pedro Sánchez, visitó la tumba de Azaña en Montauban, las playas de Argeles-sur-Mer donde malvivieron los refugiados republicanos, y Collioure, destino último de Antonio Machado. Ante la tumba del poeta, Sánchez hizo algo que ningún presidente en la democracia había hecho en más de cuarenta años: pedir perdón a los exiliados.

Machado y Azaña se vieron obligados a abandonar España. Uno de los mejores poetas que ha dado la literatura española de todos los tiempos y el presidente de la República. Dos personas dialogantes, cultas, creativas, pacíficas y sensatas. Es tarde, muy tarde. Han pasado muchos años desde que tuvieron que marcharse. España tendría que haberles pedido perdón mucho antes por la infamia. Lo hace hoy, a deshora, pero lo hace con el orgullo de recuperarles para siempre.

Pero al llegar al cementerio de Collioure, la comitiva se encontró con un grupo de manifestantes independentistas catalanes, que gritaban por la «libertad de los presos políticos». Intentaron boicotear el acto, y llamaron "fascistas" a quienes iban a homenajear a Machado, entre ellos gente de conocido republicanismo y compromiso antifascista. Un episodio lamentable, que escenificaba las tensiones políticas actuales en España. Tensiones que también tienen mucho que ver con la forma en que la democracia española ha enfrentado y resuelto su pasado reciente.

Aún podría añadir más episodios de las últimas semanas en España, como la decisión del gobierno de sacar a Franco de su mausoleo fascista en 
el Valle de los Caídos, y la resistencia que está encontrando en la oposición política, en los medios y en los jueces.

Y es que hablar de la memoria, la guerra, el exilio o Machado no es mirar atrás. Significa hablar de la España de 2019, de sus conflictos, de esta España en la que apenas queda un puñado de españoles que viviesen la guerra, y no muchos más que tengan memoria directa de la posguerra. Una relación conflictiva con el pasado que dura más de cuarenta años, y que ha ido pasando a los hijos, los nietos y hoy ya los bisnietos de quienes vivieron la Guerra Civil. Esa es la realidad en que se mueve el creador, novelista, cineasta o dramaturgo que hoy se proponga representar ese pasado con su obra. No puede ser ajeno a esa condición conflictiva de presente.

Empiezo, por situar los términos, refiriéndome al propio concepto de memoria. Me acojo a la definición que de la misma hizo Walter Benjamin, el gran pensador de la memoria, en un hermoso texto, «Excavación y Memoria».

La lengua nos indica de manera inequívoca que la memoria no es un instrumento para conocer el pasado, sino sólo su medio. La memoria es el medio de lo vivido, al igual que la tierra viene a ser el medio en que las viejas ciudades están sepultadas. Y quien quiera acercarse a lo que es su pasado sepultado tiene que comportarse como un hombre que excava. Y, sobre todo, no ha de tener reparo en volver una y otra vez al mismo asunto, en irlo revolviendo y esparciendo tal como se revuelve y esparce la tierra. Los "contenidos" no son sino esas capas que sólo después de una investigación cuidadosa entregan todo aquello por lo que vale la pena excavar: imágenes que, separadas de su conocimiento posterior, como quebrados torsos en la galería del coleccionista. Sin duda vale muchísimo la pena ir siguiendo un plan al excavar. Pero igualmente es imprescindible dar la palada a tientas hacia el oscuro reino de la Tierra, de modo que se pierde lo mejor aquel que sólo hace el inventario fiel de los hallazgos y no puede indicar en el suelo actual los lugares en donde se guarda lo antiguo. Por ello los recuerdos más veraces no tienen por qué ser informativos, sino que nos tienen que indicar el lugar en el cual los adquirió el investigador. Por tanto, stricto sensu, de manera épica y rapsódica, el recuerdo real debe suministrar al mismo tiempo una imagen de ese que recuerda, como un buen informe arqueológico no indica tan sólo aquellas capas de las que proceden los objetos hallados, sino, sobre todo, aquellas capas que antes fue preciso atravesar.

Y en otro texto, el mismo Benjamin sobre el pasado y nuestra relación conflictiva con el mismo:

Articular el pasado históricamente no significa reconocerlo «tal y como propiamente ha sido». Significa apoderarse de un recuerdo que relampaguea en el instante de un peligro. Al materialismo histórico le toca retener una 
imagen del pasado como la que imprevistamente se presenta al sujeto histórico en el instante mismo del peligro [...]. El don de encender la chispa de la esperanza solo es inherente al historiógrafo que esté convencido de que ni los muertos estarán seguros ante el enemigo si es que este vence. Y ese enemigo no ha cesado de vencer.

En esas claves nos podemos situar en esta España de 2019 donde seguimos discutiendo de huesos y fosas, de la tumba de Franco y de las tumbas pendientes de quienes siguen enterrados en fosas comunes sin identificar, del exilio y de la ultraderecha que cita a Antonio Machado.

Quiero hacer un breve repaso autobiográfico a las últimas cuatro décadas, a modo de autobiografía propia pero también colectiva, de todo un país. Me fijaré en varios momentos, uno por década, decisivos para la construcción de esa memoria, que contextualizan la forma en que la literatura se acercaba al pasado, y que explican mi propia obra hasta hoy; para después reflexionar sobre la manera en que los creadores españoles hemos representado el pasado conflictivo para los lectores actuales.

Empezamos el recorrido en los años setenta, el final de la dictadura y la Transición. Entre la incertidumbre, el miedo y la esperanza, se produce un primer impulso a la memoria democrática, de la mano de los familiares de desaparecidos. Aunque nos parezca que la búsqueda de fosas es algo de los últimos veinte años, es en ese momento, con el dictador recién muerto y su régimen todavía sin desmontar, cuando los ciudadanos empiezan a recuperar esa memoria negada durante cuarenta años.

Fue el caso de Esperanza García, huérfana de un asesinado que en el año 1977 regresó de Bélgica para buscar los restos de su padre, en la localidad palentina de Villamuriel. Tras visitar al falangista que lo asesinó, localizó el lugar exacto en el que fueron encontrados ocho cuerpos. A raíz de la apertura de esa fosa, Esperanza recibió información y peticiones de ayuda y siguió abriendo fosas en diferentes pueblos de la zona, en las que encontró entonces I50 cuerpos.

En los siguientes años, y especialmente tras las elecciones municipales de 1979 en que llegan a los ayuntamientos partidos de izquierda, se recuperan cientos de cadáveres por toda España. Exhumaciones apresuradas, sin cuidado científico, casi clandestinas, que apenas salen en la prensa, mientras a toda prisa se cambian algunos nombres de calles.

Al tiempo que la ciudadanía toma la iniciativa, el congreso aprueba la ley de amnistía. En el otoño de 1978 se presentó en Madrid en Tribunal Cívico Internacional contra los Crímenes del Franquismo. Promovido por el PCE (m-l), en él participaron responsables de organizaciones de derechos humanos, abogados y numerosos representantes del mundo de la cultura. El 28 de noviembre se reunió en Madrid la junta promotora del Tribunal, formada por diecinueve personas, que fue detenida en el Hotel Convención 
junto a cinco periodistas que cubrían el acto. Ese tribunal trataba de emular al conocido como Tribunal Russell o al Tribunal Humberto Delgado de Portugal, con el fin de que las víctimas de la dictadura franquista fueran reparadas.

No solo en la ciudadanía, también los creadores. De esos años son películas valientes, censuradas y perseguidas, como las de Basilio Martín Patino (Canciones para después de una guerra, Caudillo, Queridísimos verdugos) o de Fernando Ruiz (Rocío).

Sin apenas apoyo político e institucional, este primer movimiento de recuperación de la memoria cesa bruscamente con el golpe de Estado de febrero de 198I, que despierta otra vez el miedo y los fantasmas del pasado. La victoria del PSOE en 1982 cierra ese primer ciclo, al desactivar todo intento de diálogo con el pasado.

Como sostiene Isabel Cadenas:

Hubo, sí, cultura que trató de impugnar la manera de relacionarse con el pasado que se estaba gestando entre los Pactos de la Moncloa y la Constitución, pero en pocos años, o sería expulsada hacia los márgenes, o sería completamente invisibilizada (casi lo mismo, pero no del todo), o desaparecería. Si hubiera una línea divisoria, esta tendría que situarse en algún momento entre el golpe de Estado de I98I y la victoria del PSOE en I982 (Poética de la ausencia, 2019).

Tal vez la intensidad de aquel momento inicial, con su consiguiente agotamiento, junto al famoso «desencanto» que se produjo pasados los momentos de euforia inicial, explican el menor interés por la memoria histórica en los años siguiente, en los ochenta. Desinterés producido además por la falta de iniciativa desde las instituciones, precisamente en el momento en que gobernaba el Partido Socialista, del que tal vez cabía esperar una rehabilitación del pasado. Es ya conocida la disculpa que Felipe González expuso en un libro de conversaciones con Juan Luis Cebrián. El expresidente se reconoce «responsable de no haber suscitado un debate sobre nuestro pasado histórico, el franquismo y la Guerra Civil, en el momento en que probablemente era más oportuno». Y añade:

No hubo, no ya exaltación, ni siquiera reconocimiento, de las víctimas del franquismo, y por eso hoy yo me siento responsable de parte de la pérdida de nuestra memoria histórica, que permite ahora que la derecha se niegue a reconocer el horror que supuso la dictadura, y lo haga sin ninguna consecuencia desde el punto de vista electoral o social.

Así lo afirma la especialista en Literatura Española Jo Labanyi, citada por Isabel Cadenas: 
La ruptura que marcó la Transición fue cultural en el sentido de que los españoles se vieron envueltos en un proceso frenético por ponerse al día con los estilos de vida que marcaban la modernidad occidental [...]. Parecía que para alcanzar esos estilos de vida habría que suprimir cualquier referencia al pasado. Así, el gobierno socialista de I982-1996 lanzó una campaña de publicidad para promocionar en el extranjero productos culturales -como las películas de Almodóvar, por ejemplo- que promovieran la imagen de una España joven, atrevida y ultramoderna que era la más iconoclasta de los países europeos.

Tras esos «años perdidos» de los que hablaba Felipe González, hubo que esperar hasta finales de los noventa, momento en que concurren varios factores que explican el resurgir de la memoria: en primer lugar, la llegada a la edad adulta de una nueva generación, a la que pertenezco, la de nacidos en la democracia. En segundo lugar, la concurrencia de aniversarios (sesenta años de la Guerra Civil), que justificaron homenajes, congresos, publicaciones... Y otro motivo importante: la llegada al gobierno de la derecha, que hace que el PSOE se interese por la memoria antifranquista como un arma arrojadiza en la confrontación política.

Me fijaré en el primero de esos factores, que considero decisivo, y que es fundamental en mi interés literario y político por el pasado reciente: el relevo generacional en España. La llegada a la edad adulta de la primera generación nacida en democracia, y la sacudida que supuso en materia de políticas de memoria y revisión del pasado reciente. En el cambio de siglo, quienes nacimos en los setenta nos incorporábamos activamente a la vida pública, y nuestra mirada a la Transición y al franquismo incorporaba la superación de miedos y complejos de la generación anterior, la de nuestros padres, que vivieron el tardofranquismo y la Transición, y la de nuestros abuelos, que aún tenía recuerdo de la guerra y del primer franquismo. Eso se materializó en un cuestionamiento de la manera en que España había gestionado su pasado, la carencia de políticas de memoria democrática, y la falta de reparación a las víctimas de la dictadura.

Salvando las muchas distancias, sucedió algo similar a lo que ocurrió en España a finales de los cincuenta y primeros sesenta. Entonces se produjo un decisivo cambio generacional, cuando llegaban a la edad adulta quienes habían nacido después de la guerra, la primera generación de posguerra. Jóvenes que no habían conocido directamente la guerra ni la brutalidad de la posguerra, y que por tanto no estaban condicionados por el terror que sus padres habían vivido.

El proceso fue similar para la mayoría de jóvenes: de pronto, descubrían en su familia, en su pueblo, en su entorno inmediato (en su país, por extensión), una información que entraba en colisión con la información y educación recibidas hasta entonces. Para mí, por ejemplo, fue el momento en que 
al llegar a la universidad supe por primera vez de la matanza de Badajoz (más de cinco mil asesinados en el verano de 1936), tras haber vivido toda la infancia y adolescencia en esa ciudad sin haber recibido esa información ni por mi familia, ni en el sistema educativo, ni en ningún tipo de recuerdo público o institucional.

En todos los casos, de repente fuimos conscientes de la disfuncionalidad española, y nos rebelamos contra ella. Unos lo hicieron desde el activismo social y político (las asociaciones de recuperación de la memoria histórica, los primeros desenterramientos de fosas y homenajes desde la Transición...); otros desde la reconstrucción del relato familiar (silenciado durante décadas); y en mi caso a través de la literatura. Mi primera novela, La malamemoria, posteriormente reeditada y revisada en forma de iOtra maldita novela sobre la Guerra Civil!, es de finales de I999, solo tres meses antes del primer desenterramiento de una fosa en Priaranza del Bierzo (León). Mi inquietud al escribir coincidía con la de quienes, en la generación de los nietos, empezaba a cuestionar el relato oficial, y a exigir las reivindicaciones que desde entonces acompañan a este movimiento civil: verdad, justicia y memoria para las víctimas del franquismo. Lo que comenzó como un cuestionamiento político y cultural al relato democrático de guerra y dictadura, alcanzó inevitablemente al propio relato de la Transición, y a la democracia misma.

En ese momento, en el cambio de siglo, se produce un pico de producción editorial. Como respuesta al momento político y social, y a la demanda de memoria histórica por los ciudadanos, hay un repunte de libros sobre la guerra: ensayos, memorias, pero también novelas, muchas novelas. El título más representativo de esos años, Soldados de Salamina, de Javier Cercas, es de marzo de 200I. A partir de ahí, una riada de títulos, de novelas sobre la Guerra Civil. Entre ellas, aquella Malamemoria mía, intento juvenil de dar respuesta a mis inquietudes, de compartir ese descubrimiento, ese estupor, ese recelo; y pocos años después El vano ayer.

Saltamos diez años en este recorrido autobiográfico (personal y colectivo), hasta finales de la siguiente década, años 2007-2008. Hay un gobierno del PSOE en España que, en respuesta a la creciente demanda ciudadana, dice estar dispuesto a recuperar el tiempo perdido que decía González. Sitúa la memoria histórica en su agenda. Mientras la sociedad civil organizada desentierra fosas, realiza homenajes y acude a los tribunales, el gobierno redacta una ley que será aprobada en el Congreso: la Ley 52/2007, de 26 de diciembre, por la que se reconocen y amplían derechos y se establecen medidas en favor de quienes padecieron persecución o violencia durante la Guerra Civil y la dictadura, conocida coloquialmente como ley de la memoria. 
Una ley acogida con reservas por los familiares de víctimas, y cuya falta de desarrollo, lentitud, y finalmente paralización con la llegada del nuevo gobierno conservador, provocará decepción en el movimiento de recuperación de la memoria. Algunos ven la ley como un intento del gobierno por institucionalizar la memoria para evitar su desborde, encauzarla, dirigirla, controlarla, en un momento en que las asociaciones de familiares ya no se conforman con abrir fosas, cambiar calles u homenajear a las víctimas: piden justicia, y acuden a los tribunales.

La ley culmina ocho años donde la memoria ha estado en el centro de la agenda pública. Años de actos, congresos, acciones, publicaciones... Las librerías muestran mesas y escaparates llenos de libros sobre la Guerra Civil, las televisiones programan películas y reportajes, en algo que, perdonen la autocita, llamé en aquel momento en un artículo «Empacho de memoria». Escribí entonces (El País, julio de 2006):

Sólo llevamos seis meses del oficialmente llamado «Año de la Memoria Histórica», y algunos empezamos ya a estar un poco empachados. No es que estemos saturados de memoria, nada de eso. Pero sí empalagados por todo tipo de sucedáneos que, como golosinas, engordan pero no alimentan, engañan al hambre y hasta saben bien, pero no son muy recomendables desde el punto de vista nutricional. Trasladado el paralelismo alimenticio al debate sobre la memoria, uno tiene a veces la sensación de que, entre bocado y bocado, le cuelan cucharadas de sucedáneo dulcísimo que poco tiene que ver con la recuperación de la memoria, y sí con otro tipo de intereses. Me explico. [...]

Se trata de la respuesta «comercial» que se da al movimiento de recuperación de la memoria. Desde la industria cultural se ha detectado que, en efecto, existe un interés amplio entre los ciudadanos por todo lo que tiene que ver con la historia reciente de España, con la llamada recuperación de la memoria histórica. Eso, unido a la coincidencia de aniversarios (30 años de la muerte de Franco, 70 del inicio de la Guerra Civil, 75 de la proclamación de la Segunda República) y al impulso institucional (Año de la Memoria, programación televisiva, exposiciones y actos...), hace que algunos vean en toda esta inflación memoriosa un filón comercial.

Se trataría, en resumen, de convertir ese interés ciudadano, esa demanda de conocimiento, esa exigencia de memoria, en un acto de consumo. De ahí la sobreproducción de títulos referidos a la Guerra Civil o al franquismo que llenan las librerías. Pareciera que las editoriales han corrido a vaciar sus almacenes, recuperando títulos olvidados en sus fondos, a la vez que apremian a sus autores a producir obras relacionadas con la memoria. Librerías con mostradores monotemáticos y quioscos desbordados de coleccionables dan prueba de ello. Por debajo de esta acumulación (que, sin duda, ha permitido recuperar títulos interesantes que estaban descatalogados, y que conviven con nuevas obras de indudable valor) se aprecia un claro oportunismo por parte de algunas editoriales y también de algunos autores empeñados en no 
quedar al margen de este filón de la memoria.

Permítanme ilustrar este empacho en el terreno literario, referido a las novelas sobre la Guerra Civil, esas que, siguiendo el título de mi propia novela de 2007, haría exclamar a los lectores hastiados .

Desde hace años colecciono fragmentos de sinopsis y frases promocionales de novelas recientes sobre la Guerra Civil. En las fajas de los libros encontramos frases para atraer la atención del lector, como estas:
«Una novela que rebosa intriga, política, espionaje, amor y traición...»
«Una devastadora guerra, un gran amor no correspondido, dos heridas im- posibles de sanar.»
«Una historia memorable y trepidante que redescubre un episodio de nues- tro pasado.»
«Una hermosa y emocionante historia que descansa en la lucha contra el olvido.»
«Una preciosa novela que aúna lo terrible de la guerra con lo maravilloso del amor.»
«Amores y desamores desgarrados, aventura e historia, una novela que fas- cinará a todos aquellos interesados en nuestra propia historia.»
«Una historia de amor y de amistad que se desarrolla en las circunstancias más adversas.»
«Una historia sepultada por la Guerra Civil en la que se funden amor y po- lítica.»

Hay que reconocer el mérito de los editores para seguir creando frases a partir de unas pocas palabras combinadas hasta el infinito: guerra, amor, emocionante, trepidante... Pero como de las fajas no hay que fiarse demasiado, y a menudo son más bien disuasorias, veamos las sinopsis, el texto de contraportada que resume el argumento y el alcance de la novela. Algunas de estas sinopsis comienzan así:
«Una periodista recibe una propuesta para investigar la azarosa vida de su bisabuela...»
«El odio de dos hombres que aman a la misma mujer y a los que la guerra ha situado en bandos distintos...»
«Una historia de complicidad a través del tiempo, la que comparte una abue- la, maestra en tiempos de la República, y su nieto...»
«Tras la muerte de su madre, a Julio le es revelado un secreto familiar oculto durante medio siglo...»
«Un joven periodista se propone reconstruir el relato real de los hechos y desentrañar el secreto de sus enigmáticos protagonistas...»

Las frases citadas pertenecen a novelas publicadas en los últimos diez años. Todas en grandes editoriales, por autores reconocidos, con decenas de 
miles de lectores y gran atención mediática. Todo suena a demasiado visto, a fórmula, a lugar común mil veces visitado. A otra maldita novela....

Un congreso celebrado en Salamanca en octubre de 20I8, y que reunió a especialistas de varios países, puso cifras al fenómeno: setenta nuevas novelas sobre la Guerra Civil cada año. Según los datos recopilados por la Asociación de la Memoria Social y Democrática, durante la propia guerra y en los años posteriores se publicó una media de veinte novelas al año sobre la Guerra Civil. Algunas en el exilio, desde el punto de vista republicano, otras en la España franquista, reproduciendo la versión de los vencedores. Desde entonces el número fue creciendo, hasta llegar a esa media de setenta novedades al año desde el comienzo de este siglo. La citada asociación tiene documentadas, entre 200 y y 20I8, un total de I.248 obras. En 2015 se rozó el centenar de novelas, noventa y nueve.

Tantas, que hasta cuesta trabajo elegir un título que no esté ya usado. Hace algo más de diez años, mientras escribía ¡Otra maldita novela sobre la Guerra Civil!, hice una consulta en el ISBN, donde se registran todos los títulos publicados. En los cinco años anteriores (2002-2007) se habían publicado 4I9 obras literarias que incluían en su título la palabra memoria. No quiere decir que todos se refiriesen a la memoria de la Guerra Civil, pero eran años donde la memoria histórica estaba muy presente en la agenda mediática y política. Por comparación, en toda la década anterior, los años noventa, solo 289 títulos literarios incluían la palabra memoria.

Entre esos más de 400, algunos ejemplos: La memoria prohibida, La memoria inútil, La casa de la memoria, El perfume de la memoria, Memoria arrodillada, Azul es la memoria, La sombra de la memoria, En los campos de la memoria, El latido de la memoria... Otras versiones jugaban con la zoología: La memoria del gallo, La memoria de los peces, La memoria de los lobos. Y había también títulos reversibles: había una Memoria del corazón, pero también El corazón de la memoria. La memoria de cristal, y poco después El cristal de la memoria. Los espejos de la memoria, y La memoria de los espejos. De modo que si querías titular tu libro La memoria de la luz, o La memoria del barro, y descubrías que ya estaban usados, podías optar por La luz de la memoria, o El barro de la memoria. ¿Qué ya está cogido La piel de la memoria? Pues prueba con La memoria de la piel, que no desmerece nada.

¿Y entonces? ¿Tenemos demasiadas novelas sobre la Guerra Civil? Eso podría pensar el lector al entrar en la librería, o cualquiera que lea mi listado de títulos y sinopsis. Son demasiadas. ¿Seguro? Tengo dudas. Son muchas, pero no son demasiadas. Quizás ni siquiera son muchas. No muchas más que las que anualmente se publican sobre los nazis y el Holocausto, o las novelas históricas sobre determinadas épocas, o las incontables novelas negras y detectivescas, o las novelas metaliterarias protagonizadas por novelistas, o la omnipresente autoficción. Además, de esas setenta novelas 
anuales, casi la tercera parte son autoediciones, que apenas tienen distribución, que no llenan los mostradores de las librerías. Aun nos quedaría medio centenar cada año, que insisto, parece una gran cantidad, pero en realidad muy modesta comparada con las miles de novedades de narrativa que se editan anualmente. Diría que incluso insignificante si lo comparamos con la presencia que el pasado, la guerra, la memoria, siguen teniendo en el debate ciudadano, político, mediático.

Y sin embargo, está muy extendida la idea de que ya hemos escrito demasiado de la Guerra Civil. Que ya está bien. Vale ya. No cabe una más. No hay escritor español que no haya escrito su novela de la Guerra Civil. Pasa lo mismo con el cine: cuántas veces hemos oído eso de que el cine español solo hace películas de la Guerra Civil. A quien lo diga, pregúntenle cinco títulos de los últimos cinco años que traten de la guerra, solo cinco títulos. Verán como les cuesta encontrar esos cinco títulos.

No es cierto, no hemos escrito tanto. De hecho, queda mucho por escribir. Frente a la idea de las malditas novelas sobre la Guerra Civil, yo digo que faltan novelas. No malditas, sino benditas novelas, que consigan aquello que no consiguen todas las mencionadas y muchas otras de esas más de setenta que se editan cada año. Porque el problema no es de cantidad. Es sobre todo de calidad. De calidad literaria, por supuesto, pero también de calidad histórica, de calidad política, de calidad humana, de calidad cívica. Tenemos muchas novelas de la Guerra Civil, pero muy pocas que nos sirvan para entender aquel tiempo, y menos aún que nos sirvan para entender el presente con esa mirada al pasado.

Habrá quien, tras escuchar mi lista inicial de títulos, sinopsis y frases promocionales, piense: vale, Isaac, pero has hecho trampas, porque todas esas son novelas comerciales, no pretenden otra cosa, no engañan a nadie, qué tienen de malo. Es más, sucede lo mismo con otros períodos históricos trágicos, a los que también acuden autores comerciales buscando un escenario fácil, reconocible, atractivo, inagotable, en el que ambientar sus ficciones, y con recursos emocionales que ganan al lector sin mucho esfuerzo.

El nazismo y el Holocausto, por ejemplo. Las librerías están llenas de niños con pijama de rayas, y La bibliotecaria de Auschwitz, y El mago de Auschwitz, y La canción de Auschwitz, La bailarina de Auschwitz, El farmacéutico de Auschwitz, Un amor en Auschwitz, El violín de Auschwitz, La canción de Auschwitz, El tatuador de Auschwitz...Todos con su faja promocional que pone basada en una inolvidable historia real, y Una historia de superación, amor y amistad en medio del horror.

Hace unos años el historiador francés George Didi-Huberman, ante los muchos eventos que conmemoraban el 60 aniversario de la liberación de Auschwitz, advertía que la memoria de Auschwitz se había convertido en una memoria saturada: una memoria saturada es aquella que pierde efecti- 
vidad histórica, una memoria en la que el evento que se recuerda está desligado de las condiciones históricas que lo hicieron posible.

Si la del Holocausto es una memoria saturada, ¿en qué medida lo sería la memoria de la Guerra Civil? Saturación, o empacho, usando la expresión que recuperé antes de un artículo propio. Un interés comercial, convertir el interés ciudadano en acto de consumo. Pero también, desde un punto de vista político, en la saturación o el empacho hay un intento de controlar y desactivar el empuje ciudadano en pos de la memoria histórica.

Pero vuelvo a la comparación que antes hice con el nazismo y el Holocausto. ¿Por qué aceptamos, o no somos tan críticos, con su saturación o su comercialización, y sí lo somos, yo al menos, en lo que se refiere a la Guerra Civil o la dictadura?

Evidentemente, porque las consecuencias en un caso $\mathrm{u}$ otro son muy diferentes. Las consecuencias sobre los lectores, es decir, sobre los ciudadanos. El punto de partida es muy distinto, y por tanto el terreno en el que se mueven los creadores, novelistas en este caso, es bien diferente, y las consecuencias de sus obras, y por tanto su responsabilidad como autores, no tiene el mismo alcance.

Ello se debe a la manera en que se ha construido la memoria democrática, término que me gusta más que memoria histórica, y al que añadiría memoria democrática y antifascista, la forma en que se ha construido en España, y el papel que la cultura ha jugado en ese proceso. Y ahora ya no estoy hablando solo de la literatura comercial, sino también de aquellos otros autores que con las mejores intenciones, incluso desde presupuestos reivindicativos y de reparación a las víctimas, han fallado, o hemos fallado, en ese propósito.

En mi libro ¡Otra maldita novela sobre la Guerra Civil!, terminaba así:

Nos tememos que, una vez más, la guerra, la memoria, las víctimas, se conviertan en pretexto narrativo, y lo que se pretendía una novela revulsiva se conforma con una historia entretenida, un ejercicio de estilo, una convencional trama de autoconocimiento y, por supuesto, de amor. Eso sí, con la Guerra Civil al fondo, actuando de referente atractivo, reconocible, donde el lector se siente cómodo y se muestra curioso. Novelas como ésta pueden hacer más daño que bien en la construcción del discurso sobre el pasado, por muy buenas intenciones que declaren. Debido a las peculiaridades del caso español, a la defectuosa relación que tenemos con nuestro pasado reciente, la ficción viene ocupando, en la fijación de ese discurso, un lugar central que tal vez no debería corresponderle, al menos no en esa medida. Y sin embargo, lo ocupa, lo quiera o no el autor, que tiene que estar a la altura de esa responsabilidad añadida. 
Permítanme que me detenga brevemente en esas peculiaridades, y en esa idea de responsabilidad del autor.

A los españoles, la Guerra Civil nos la han contado los novelistas. También los cineastas, los dramaturgos o las series de televisión. Los creadores de ficción. Esto puede parecer una obviedad, pues sirve para cualquier suceso histórico, cuya imagen, cuyo relato, quedan fijados por la ficción. Pensemos otra vez en la Segunda Guerra Mundial, donde a pesar de la enorme producción historiográfica, el relato que la mayoría de ciudadanos hemos consumido viene de novelas y sobre todo películas, especialmente cine norteamericano, empeñado en hacer pasar por histórica una visión ideológica. Y lo mismo podríamos decir de cualquier suceso histórico.

$\mathrm{Y}$ tampoco se trata de reivindicar para los historiadores un monopolio que nunca han tenido, pues, como recordaba una obra colectiva de jóvenes historiadores de hace unos años,

el pasado se enseña en la escuela, el instituto o la universidad, pero se aprende en otros muchos lugares, institucionalizados o no, y por muchas otras vías, tanto formales como informales.

Para los historiadores, acostumbrados a escribir libros de historia y a considerar -sin malicia- al resto del mundo como su audiencia, los manuales escolares y los planes de estudio son más visibles y fáciles de explicar que las variadas dinámicas del aprendizaje de la historia (de la memoria familiar, comunitaria e individual al videojuego, pasando por la publicidad, las películas y documentales, las novelas, o la mera contemplación de restos del pasado, etc.).

Pero en el caso de la Guerra Civil y el franquismo, esto sucede de una manera acusada, y diría desequilibrada. Durante muchos años la literatura, el cine, el teatro, han ocupado un espacio que no les correspondía, o un espacio mayor del que les correspondía. Ante la ausencia de otros agentes responsables de construir ese relato, ha sido la ficción la que ha ocupado el terreno del que otros desertaran. Tiene que ver con la forma en que se ha gestionado el pasado reciente en España durante la Transición y ya en democracia, y el fracaso de las instituciones, el sistema educativo y hasta parte de la historiografía en elaborar ese relato del pasado.

Lo decía recientemente el historiador Ángel Viñas: la democracia española ha fracasado estrepitosamente al no haber construido un relato más o menos aceptable y fundado documentalmente sobre lo que supuso la Guerra Civil.

No es que sea un drama, para los franceses el relato sobre lo que fue Vichy ha costado un montón de años. Lo mismo pasa en Italia, uno de los perdedores de la II Guerra Mundial. Pero aquí, francamente, el poder público se ha inhibido, y el sistema educativo no ha proporcionado elementos de 
interpretación a los alumnos. Dos generaciones han acabado la ESO, la FP o lo que sea, sin haber tenido informaciones básicas sobre lo que fue la República, la Guerra Civil y la dictadura. Estos olvidos se pagan en ignorancia, desafección, y en que una parte de la población está presa de argumentaciones sin el menor valor histórico. Pero como los hechos para estos políticos no cuentan, y los desfiguran, estamos donde tarde o temprano tendríamos que llegar...

Esas son las disfunciones de la memoria en España. El fracaso, la incomparecencia, de aquellos agentes responsables de construir esa memoria democrática y antifascista. El Estado en primer lugar, las instituciones públicas. El sistema educativo, como transmisor de valores democráticos. La universidad, con muchos agujeros en la investigación, que han llevado a nuevos historiadores, jóvenes, locales, a trabajar al margen de ella. Los medios de comunicación... Todos han fallado, fracasado, o no comparecido, y han dejado el terreno despejado, libre, para que lo ocupen otros. Los revisionistas, los neofranquistas, que siguen encontrando audiencia a su propaganda. Pero también los creadores, que hemos plantado nuestras obras en un terreno despejado, ocupando así más espacio del que tal vez nos correspondería.

Tampoco se trata de reclamar un relato oficial, único, una verdad totalizadora, que de eso ya tuvimos en el franquismo. Nada de eso. El pasado siempre será motivo de controversia, la disputa por el relato está en su esencia, será siempre un campo de batalla, y toda memoria es conflictiva, tanto más la llamada memoria colectiva o memoria histórica, que ni suele tener una autoría colectiva (hay agentes hegemónicos siempre); ni a menudo tiene mucha base histórica. Pero sí unos mínimos, fijados institucionalmente, y que sirvan para la transmisión en el sistema educativo, y para el recuerdo, homenaje y reparación de las víctimas. Pasa en cualquier país con pasado conflictivo, donde sigue habiendo polémicas, pero existen esos mínimos y esos espacios de reparación. Pasa en el caso, obviamente, del nazismo y el Holocausto. Podemos discutir, pero a partir de esos mínimos aceptados por todos, y el que se aparta en seguida es desacreditado como revisionista, negacionista, e incluso perseguido penalmente. Aquí no.

Por eso, cuando uno decide escribir una novela sobre la Guerra Civil (y qué novelista español no lo hace en algún momento), debe saber que no lo hace en el mismo terreno de juego ni con las mismas reglas que cuando un novelista austríaco decide escribir sobre el nazismo. Debe saber que su novela va a ser leída por una ciudadanía que con demasiada frecuencia no ha recibido otros relatos, y se va a construir su imagen del pasado, su memoria, a partir de esa novela.

Eso implica, por supuesto, una responsabilidad, de la que el novelista no puede desentenderse aunque quiera. Uno no puede excusarse diciendo que 
ha escrito una novela histórica, o de intriga, o de amor, de entretenimiento, comercial, ambientada en la Guerra Civil; porque lo quiera o no, va a ser leída como una propuesta de relato, como una interpretación de la Guerra Civil, y va a actuar en un terreno de juego conflictivo, en un campo de batalla.

Hablaba de responsabilidad, y podría hablar de consecuencias. El novelista que mira a la Guerra Civil no puede pretender ser inocente, tiene que asumir las consecuencias de su escritura. Una expresión de Rafael Chirbes que hago mía: se refería él a la excitante responsabilidad civil de la escritura. Chirbes, que nunca escribía en vano y escogía bien las palabras, usa el término responsabilidad civil, que es jurídico, y se refiere al daño causado y la reparación del mismo. También los autores tenemos una responsabilidad civil con nuestras obras. Y en el caso de la Guerra Civil y el franquismo, de forma muy acusada.

¿De qué manera hemos novelado la Guerra Civil en los últimos años? Generalizando, siendo por tanto injusto, diría que hemos convertido la literatura de la Guerra Civil en un género, o un subgénero literario. Con todas las excepciones que quieran, son habituales las novelas que reproducen formas, argumentos, tramas, tratamientos, personajes, técnicas, lenguajes, visiones históricas, y una muy extendida sentimentalización... Hasta darles un color reconocible, un aire de familia, que las vuelve convencionales, las desactiva, las hace inofensivas.

El planteamiento de partida habitual suele arrancar en el presente, para desde ahí viajar al pasado y hacer un descubrimiento, desvelar un secreto, cuyas consecuencias sobre el presente sin embargo quedan amortiguadas, sin continuidad histórica. El pasado como un tiempo cerrado, lejano, acabado.

¿Cuántas novelas hemos leído en que el protagonista es un periodista que inicia una investigación que le llevará a descubrir un episodio oculto de la Guerra Civil (fórmula puesta de moda por Soldados de Salamina y mil veces imitada)? ¿Cuántas donde un detective investiga un crimen del presente y acaba tirando del hilo que le conduce a una venganza aplazada desde la Guerra Civil? ¿Cuántos dramas familiares que hunden sus raíces en un amor trágico o un enfrentamiento fratricida al calor de la Guerra?

¿Cuántas veces hemos encontrado en novelas señoritos falangistas, anarquistas autodidactas, comunistas intrigantes, milicianas adelantadas a su tiempo y niños que aportan el inevitable punto de vista infantil que nos conmueve? ¿Cuántas veces insisten los novelistas en que sus obras se basan en hechos reales, para lograr en los lectores no sólo el asentimiento poético propio de la ficción, sino también el más rotundo asentimiento histórico? ¿Y qué me dicen de esos personajes que tienen la virtud de estar siempre en el momento y el lugar precisos para presenciar un acontecimiento histórico, para ponérselo fácil al narrador y que pueda contárnoslo? ¿Cuántas 
descripciones y cuántas caracterizaciones nos provocan sensación de "déjà vu" cuando nos las volvemos a encontrar en una novela? ¿Cuántas veces, en efecto, exclamamos eso de ¡Otra maldita novela...! ante narraciones previsibles, inofensivas, que se ajustan a las reglas del género?

La profesora Celia Fernández Prieto habla de

novelas de plantilla, cauterizadoras, terapéuticas, que reiteran hasta la saturación una serie limitada de esquemas y convenciones narrativos, que se complacen en el trazado grueso y esperpéntico hasta sepultar la realidad de una dictadura que ejerció como tal hasta el último día. Las novelas o las películas, por su potente capacidad de simbolización, pueden reducir la vida, la memoria y el lenguaje al estereotipo.

En palabras de Jaume Peris Blanes:

Los discursos y representaciones de la Guerra Civil han sido absorbidos por una emergente industria cultural de la memoria. Ello somete a buena parte de estos textos a las exigencias productivas de la industria, y mezcla los criterios artísticos, académicos e ideológicos con la necesidad de rentabilidad comercial, privilegiando por ejemplo los componentes dramáticos y narrativos de la Historia.

Y esto no solo es aplicable a la narrativa de vocación comercial. Sucede también en obras que diríamos bienintencionadas, de autores afines, comprometidos cuando no militantes que se proponen una reivindicación y reparación de las víctimas, pero que con frecuencia no consiguen escapar a las servidumbres de esa literatura de género.

Lo ha analizado bien el investigador David Becerra en un ensayo de título provocador: La Guerra Civil como moda literaria. Con vehemencia, Becerra señala la manera en que

buena parte de las novelas de los últimos años (las que más atención editorial y mediática reciben, las más vendidas y premiadas), reproducen dos consensos: el consenso de la Transición (en términos de amnesia, amnistía y equidistancia), y el consenso neoliberal (que sostiene que vivimos tiempos post-políticos y hemos alcanzado el "fin de la historia").

El resultado, obras aproblemáticas, inofensivas. Así lo analiza Isabel Cadenas en su ensayo Poética de la Ausencia:

La mayoría de las obras han seguido una serie de pautas -tácitas pero imperantes- para hablar del pasado. Según esas pautas, del pasado se puede hablar, pero siempre: a) de una manera eminentemente narrativa -siempre estableciendo un continuum en la historia-, b) trasladándose al pasado, sin 
establecer dialéctica alguna con el presente -no hay, pues, influencia del pasado en el presente, no es un pasado que reverbera-, y c) extendiendo sobre ese pasado el velo de la reconciliación. Son historias tediosamente predecibles, desde series de TV hasta películas y novelas: los ganadores de la guerra son en general malísimos, los perdedores, a pesar de haber perdido, o precisamente por eso, tienen la dignidad del vencido que les permite salir adelante, son humildes y, sobre todo, saben perdonar. Ahí está el miliciano perdonavidas de Soldados de Salamina, la trabajadora y sumisa familia Alcántara de la serie Cuéntame. Historias exclusivamente personales, desligadas de las condiciones históricas que las hacen posibles, "narradas" desde un punto de vista claramente aproblemático.

Y añade Isabel Cadenas: así funciona la saturación: vivimos bajo la ilusión de que no paramos de hablar sobre la Guerra Civil y la dictadura, pero en realidad se trata de obras inofensivas, en las que cualquier potencial político está desactivado.

Y David Becerra va un paso más allá en su crítica al modelo literario y sus consecuencias políticas en el presente:

\begin{abstract}
Mediante su lectura acudimos a una reconstrucción despolitizada y deshistorizada de la Historia, invitando al lector a mantener una relación complaciente con su pasado. Estas novelas, como el espejo posmoderno de Jameson, hechizan al lector por medio de sugerentes aventuras de pasión y muerte, de vidas heroicas, de ideales y de un futuro todavía por escribir. El espejo emite un destello de luz, siempre cegador, que impide al lector reconocerse en su pasado, experimentar la Historia de forma activa, al concebir el pasado como algo que le es ajeno. Pero a su vez estas novelas legitiman la concepción de que nuestro presente, por oposición al mundo al que la narración nos retrotrae, es un presente en el que no existen conflictos y en el que, en definitiva, la Historia ha alcanzado su fin. Esta concepción sobre el pasado y el presente que esta literatura alimenta tiene unas consecuencias políticas evidentes, pues no contribuyen sino a la desactivación política del lector que, a la vez que deja de reconocerse en la Historia, asume que habita en el mejor de los mundos posibles.
\end{abstract}

En definitiva, esquemas de interpretación más o menos invariables, con tendencia a simplificar, mitificar o incluso trivializar el pasado, y que en vez de ofrecer una visión crítica del pasado, nos ofrecen un consuelo en forma de nostalgia; y que en vez de arrojar una mirada crítica sobre el presente, nos reconcilian con el tiempo que vivimos. Una memoria desactivada, una memoria inofensiva, una memoria sentimentalizada, que acaba teniendo consecuencias sobre el presente.

Berna, abril de 2019 
